\title{
THE EURIBOR AND EONIA REFORM: ACHIEVING REGULATORY COMPLIANCE WHILE PROTECTING FINANCIAL STABILITY
}

\section{Randy Priem ${ }^{1+}$ \\ Ward Van Rie $^{2}$}

\author{
${ }^{\prime}$ Katholieke Universiteit Leuven, Universite Saint-Louis, and Financial \\ Services and Markets Authority, Belgium. \\ Email:randy.priem@fsma.be Tel: +32494403601 \\ ${ }^{2}$ Financial Services and Markets Authority, Belgium. \\ Email:Ward.Vanrie@fsma.be Tel:+32473723335
}

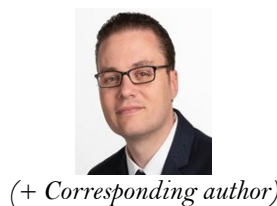

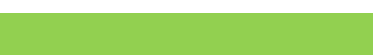

Article History

Received: 22 September 2020 Revised: 26 October 2020 Accepted: 6 November 2020 Published: 18 November 2020

\section{Keywords}

Benchmarks

Indices

EURIBOR

EONIA

Regulation

Risk-free rates.

JEL Classification:

E43, E44, G18, G21, G28, K23.

\section{ABSTRACT}

Based on an extensive review of the academic and legal literature combined with a screening of news articles and policy papers, this article is the first to describe in great detail the events leading up to the EURIBOR reform and the efforts to make EURIBOR compliant with the European Benchmark Regulation. It documents the development of the hybrid EURIBOR methodology to ensure the benchmark to be anchored to transactions as much as possible thereby reducing manipulative behavior. The article further explains the actions undertaken by the administration and the EU RFR Working Group to transition from EONIA towards €STER and the reasoning behind the choice to recalibrate EONIA into $€$ STER plus a spread. Although EURIBOR is considered BMR-compliant since 2 July 2019 and EONIA can continue to be used until 3 January 2022, this article explains why market participants should not be disincentivized to already take actions to provide for fallback rates to EURIBOR in their legal documentation, and to move away from EONIA. This study addresses various fallback methodologies.

Contribution/Originality: This study is the first to provide a holistic overview of the reforms of the EURIBOR and the EONIA, as well as the on-going work to transition away from EONIA towards the Euro short-term rate (ESTER). The study documents the efforts made by the administrator, the panel banks as well as by the FSMA to reform EURIBOR and to keep it operational, at least in the medium term. It explains the choice of the EU RFR Working Group and the administrator to recalibrate EONIA into €ster + a spread of 8.5 basis points.

\section{INTRODUCTION}

Since the late 1960s, interbank offered rates (IBORs) have played a critical role in financial markets (see Hou and Skeie (2014)). Initially used in the syndicated loan market, IBORs are nowadays considered as interest rate benchmarks ${ }^{1}$ that intend to represent the unsecured funding cost for financially sound banks in the interbank

\footnotetext{
${ }^{1}$ In this article, a benchmark is defined as in article 3 of Regulation (EU) 2016/1011 of the European Parliament and of the Council of 8 June 2016 on indices used as benchmarks in financial instruments and financial contracts or to measure the performance of investment funds and amending Directives 2008/48/EC and 2014/17/EU and Regulation (EU) No 596/2014 ("BMR"). That is, it is an index by reference to which the amount payable under a financial instrument or a financial contract, or the value of a financial instrument, is determined, or an index that is used to measure the performance of an investment fund to track the return of such 
market. IBORs are typically based on input data provided by contributing panel banks and are administered ${ }^{2}$ in one country but used in trillions worth of financial contracts by credit institutions and consumers located all over the world. IBORs are generally used by market participants as a reference rate for the interest rates embedded in their financial products and therefore to determine the amounts payable by the parties to the financial product. Practitioners often use them for valuation and discounting purposes. Central banks use them to monitor whether their monetary policy decisions took effect. The financial industry furthermore relies on them for the performance measurement of investment funds, and to compute the performance fees of asset managers. The IBORs are also indicators of the health of financial markets, e.g. when comparing them to other benchmark rates (Kloster \& Syrstad, 2019). For instance, the LIBOR-OIS spread - where OIS stands for the overnight indexed swap rate (i.e. the fixed coupon for an interest rate swap in which the floating leg is linked to an overnight rate) - is considered a key measure of the level of credit risk within the banking sector. Even as the IBORs reflect the funding cost of financially sound banks, they contain a certain level of credit risk. For OIS rates, however, credit risk is less important, since the counterparties do not exchange principal but only the difference between two interest rate streams. Under normal market conditions, both the IBORs and the OIS rates contain the same expectations about the evolution of short-term interest rates. An increasing spread signals the presence of credit concerns, as banks will ask a premium to set off this risk.

\subsection{The Manipulation of the IBORs.}

During the global financial crisis, market watchers began to raise doubts about the representativeness of the quote-based IBORs, as they did not appear to be as volatile as expected, given that they were supposed to reflect the rates at which banks borrowed interbank unsecured funds. In 2008, a series of Wall Street Journal articles were published that questioned the integrity of the London Interbank Offered Rate (LIBOR). ${ }^{3}$ It appeared that the spread between LIBOR and the TED (i.e. the three-month treasury bill rate in the US) began to diverge where they had historically been close. In addition, the rates for the credit default swaps on certain banks rose; showing a larger credit risk, but this was not reflected in their LIBOR submissions. With the start of the subprime market turmoil, LIBOR and the Euro Interbank Offered Rate (EURIBOR), who historically tended to move in the same direction, started to diverge from each other whereby LIBOR decreased and EURIBOR increased.

Already in the fall of 2007 , authorities received information pointing towards problems with the accuracy of LIBOR, indicating submissions were being set unrealistically low. In April 2010, Snider and Youle demonstrated that LIBOR indeed did not accurately reflect the average borrowing costs of banks. They presented evidence that several banks had large portfolio exposures to LIBOR and profited from its rapid descent. In their opinion, these exposures may have been the source of misreporting incentives. ${ }^{4}$ It appeared that the manipulation of the IBORs

\footnotetext{
and b) that is regularly determined entirely or partially by the application of a formula or another method or calculation, or by an assessment; and, based on the value of one or more underlying assets or prices, including estimated prices, actual or estimated interest rates, quotes, and committed quotes, or other values or surveys. The BMR defines an administrator as a natural or legal person that has control over the provision of a benchmark. A provision of a benchmark is defined as a) administering the arrangements for determining a benchmark, b) collecting, analyzing or processing input data to determine a benchmark, and c) determining a benchmark through the application of a formula or other method of calculation or by an assessment of input data provided for that purpose.

2 The BMR defines an administrator as a natural or legal person that has control over the provision of a benchmark. A provision of a benchmark is defined as a) administering the arrangements for determining a benchmark, b) collecting, analyzing or processing input data to determine a benchmark, and c) determining a benchmark through the application of a formula or other method of calculation or by an assessment of input data provided for that purpose.

${ }^{3}$ See e.g. http://www.wsj.com/articles/SB120831164167818299 and https://www.wsj.com/articles/SB121200
}

$\underline{703762}$.

${ }^{4}$ Previously, academics did not find any indication based on the data that there was a manipulation of the quotes and that the observed anomalies merely reflected elevated volatility (Abrantes-Metz, Kraten, Metz, \& Seow, 2012; Gyntelberg \& Wooldridge, 2008). 
started as early as 2005. ${ }^{5}$ Investigations showed that manipulation was widespread as demonstrated by emails and transcripts of telephone conversations between traders and submitters in certain banks. During often very informal conversations - where they addressed each other as 'dudes' with occasional swearwords - they illicitly requested to manipulate submissions (McConnell, 2013). This behavior negatively affected the reputation of those banks as well as the confidence of market participants in the financial system as a whole. A first motive for the manipulation was a credit-signaling (or stigma) effect. As the individual submissions of panel banks were published on the website of the administrators, external observers could interpret the submissions of a contributor as an indication of its creditworthiness. Contributors thus had an incentive to, especially during periods of severe market stress; lower their submissions to create a more positive perception. A second motive came from the fact that contributing banks are also benchmark users and thus have assets and liabilities with sensitivities to changes in their value. This created a conflict of interest and incentivized traders to manipulate the overall rate through their submissions for the benefit of particular trading exposures. Conflicts of interests also created the possibility of collusion between panel banks, effectively resulting in structures resembling a cartel. The investigations brought to light structural problems on the level of the contributors and the administrators. Concerning the administration of LIBOR, the Wheatley review (see infra) identified as weaknesses: the insufficient independence of the governance structures, a lack of systematic oversight of the systems and controls within administrators and contributors, and limited transparency and accountability of the governance structures. At the level of the contributors, Chinese walls separating traders and submitters, if at all in place, were rather thin. This allowed traders to liaise with submitters to have the contributed input data reflecting the request of the traders rather than the underlying market. In certain panel banks, the submitters even held an active role as traders in the derivatives referring to the benchmark. Remuneration based on company performance also gave submitters an incentive to manipulate (McConnell, 2013).

\subsection{Regulatory Actions}

Despite the sanctions imposed on the responsible parties, the IBORs did not disappear, nor did they lose their systemic importance. Efforts were, however, undertaken to increase the oversight and accountability of the entire benchmark lifecycle. Numerous regulatory principles and guidelines were drafted to address the concerns about the appropriateness of the processes and methodologies used in determining benchmarks. Examples were the UK Treasury Wheatley Review of Libor ${ }^{6}$ in 2012, the EBA / ESMA Principles for Benchmark-Setting Processes in the $\mathrm{EU}^{7}$ in 2013, and the International Organization of Securities Commissions (IOSCO) Principles on Financial Benchmarks $^{8}$ in 2013. The Financial Stability Board (FSB) and the G20 endorsed the IOSCO standards in September 2013. Following the publication of the IOSCO Principles of Benchmarks, an IOSCO task force undertook two reviews of the degree of implementation of the principles by the administrators of EURIBOR, LIBOR, and TIBOR. ${ }^{9}$ As IOSCO expects benchmark administrators to publicly disclose the extent of their compliance with the Principles on an annual basis, it also published Guidance ${ }^{10}$ for administrators to increase the consistency and quality of that reporting.

\footnotetext{
${ }^{5}$ For the BBC article on this matter, see https://www.bbc.com/news/business-18671255.

${ }^{6}$ See https://assets.publishing.service.gov.uk/government/uploads/system/uploads/attachment_data/file/191762

/wheatley_review_libor_finalreport_280912.pdf

${ }^{7}$ See https://www.esma.europa.eu/sites/default/files/library/2015/11/2013-659_esma-a_principles_for_benchm

ark-setting_processes_in_the_eu.pdf

${ }^{8}$ See https://www.iosco.org/library/pubdocs/pdf/IOSCOPD415.pdf

${ }^{9}$ See https://www.fsb.org/wp-content/uploads/r_140722a.pdf for the first review and https://www.iosco.org

/library/pubdocs/pdf/IOSCOPD526.pdf for the second review.

${ }^{10}$ See http://www.iosco.org/library/pubdocs/pdf/IOSCOPD549.pdf
} 
In 2014, the Official Sector Steering Group (OSSG) of the FSB published a report on the reform on major interest rate benchmarks ${ }^{11}$ with the help of a market participants group. The FSB stated that having a range of reference rates (i.e. a multi-rate approach) is preferred as it offers market participants the possibility to select the benchmark that best fits their needs. This multi-rate approach entails the existing IBORs to be reformed, thereby anchoring them to the greatest extent possible in transaction data ${ }^{12}$, while the market develops alternative risk-free rates (RFRs) as alternatives to the IBORs, based on e.g. overnight trades where liquidity is sufficiently deep to allow the rate to be strongly anchored in transactions. Yet, benchmarks with a credit risk component, such as the IBORs, do still serve a purpose, especially for products where there is a need to hedge bank credit risk, such as mortgages and other bank-provided credit products. ${ }^{13}$ Such a multi-rate approach would move the market away from reliance on a single, dominant reference rate, making the financial system as a whole more resilient to market disruptions involving that benchmark. Since the publication of the report, various IBORs have been reformed (see infra) and users have started to transition to new RFRs, such as the Secured Overnight Finance Rate (SOFR) in the USA, the Sterling Overnight Index Average (SONIA) in the UK, and the Euro Short-term Rate (ESTER) in the Eurozone. Similar evolutions are observed in other jurisdictions, including Australia (AONIA), Canada (CORRA), Japan (TONA), Hong Kong (HONIA), and Singapore (SORA).

In July 2016, the FSB OSSG launched an initiative to improve contract robustness to address risks of discontinuation of widely used interest rate benchmarks. The FSB OSSG invited the International Swaps and Derivatives Association (ISDA) to lead this initiative. Since the invitation, ISDA launched several consultations on fallbacks for benchmarks used in derivatives for the various currencies in which the benchmarks are published (see infra). In January 2018, IOSCO published a statement setting out considerations for users of financial benchmarks while selecting a benchmark in a contingency planning,. ${ }^{14}$ The FSB in turn published a statement on overnight riskfree rates, term rates, and fallbacks in the context of the benchmark reform. ${ }^{15}$ In this statement, the FSB explicitly acknowledged that the developed overnight RFRs are robust because they are anchored in active, liquid underlying markets. To enhance financial stability, the FSB continued to encourage the development and adoption of overnight RFRs where appropriate. However, as overnight RFRs might not always be the optimal rate to be used, the FSB reiterated in the statement its preference for a multi-rate approach.

In parallel to the work of international bodies like IOSCO and the FSB, European legislators preferred a unified European approach to avoid that individual Member States would implement the IOSCO principles in national legislation in a different manner. To ensure harmonized hard-law rules, and in addition to the introduction of a sanctioning regime via the new Market Abuse Regulation which entered into force in 2014 ${ }^{16}$, the European

\footnotetext{
${ }^{11}$ See http://www.financialstabilityboard.org/publications/r_140722b.pdf.

${ }^{12}$ In case of transaction data, it is more difficult for contributors to present inaccurate submissions to steer the direction of the benchmark. Yet, in case there is insufficient transaction data available because of e.g. an illiquid underlying market, contributors could use transactions in that underlying market to steer the benchmark. It is therefore important that benchmarks are anchored to transaction data and that the latter are available in abundance.

${ }^{13}$ If a credit institution issues a floating-rate loan and funds the loan by borrowing in the (wholesale) unsecured money market, the bank's funding cost is exposed to both market risk (i.e. interest rate risk) and the bank's credit spreads. If the floating-rate loan would reference an index being a risk-free rate, the bank has hedged only the component of its funding cost that is related to the risk-free rate and not the credit risk.

${ }^{14}$ See http://www.iosco.org/library/pubdocs/pdf/IOSCOPD589.pdf

${ }^{15}$ See https://www.fsb.org/wp-content/uploads/P120718.pdf

${ }_{16}$ Point d of article 12 (1) of Regulation (EU) No 596/2014 of the European Parliament and of the Council of 16 April 2014 on market abuse (market abuse regulation) and repealing Directive 2003/6/EC and Commission Directives 2003/124/EC, 2003/125/EC and 2004/72/EC now considers transmitting false or misleading information or providing false or misleading inputs concerning a benchmark as market manipulation if the person who made the transmission or provided the input know or ought to have known that it was false or misleading, or any other behavior which manipulates the calculation of a benchmark. Point $d$ of article
} 
Commission published in 2013 a draft proposal for a specific regulation on Benchmarks. As soon as the draft proposal was published and given the systemic importance of EURIBOR, the Belgian Financial Services and Market Authority (FSMA), who participated in the two IOSCO reviews, entered into a preparatory dialogue with the benchmarks administrator, the European Money Markets Institute (EMMI), and started putting in place the tools to ensure adequate supervision. The European Benchmark Regulation (BMR) was eventually adopted and published on 30 June 2016. ${ }^{17}$ The BMR entered into force in June 2016 and applied from 1 January 2018, although it included a transition period for existing benchmark administrators to apply for authorization or registration by 1 January 2020. The BMR, in line with the IOSCO Principles for Financial Benchmarks, has as objective to ensure the integrity of benchmarks and the benchmark determination process. It requires benchmark administrators to implement adequate governance arrangements, to identify, prevent and manage conflicts of interest, to install an oversight function, keep effective records, have internal and external audits, and have complaints handling mechanisms. In addition, the BMR requires the administrator to develop a code of conduct specifying the obligations and responsibilities of the contributors to the benchmark. For supervised contributors, i.e. contributors that are themselves already subject to regulation and supervision, the BMR directly imposes governance and control requirements on them to ensure that the input data is accurate and conforms to the BMR and the administrator's requirements as set out in the code of conduct.

As a benchmark intends to measure a certain underlying economic reality, there is an important role for the administrator as the recipient of the input data to evaluate its integrity and accuracy. If an administrator would consider that the input data does not, or no longer, represent the defined market or economic reality, it will need to take necessary measures to remedy the situation, e.g. by redefining the eligible input data or the methodology, by reviewing the contributors or even by ceasing the benchmark.

\subsection{Literature Review and Novelty of This Article}

Regarding the manipulation of the LIBOR, the literature is steadily growing (see e.g. (Abrantes-Metz et al., 2012; Ashton \& Christophers, 2015; Brainbridge, 2013; Duffie \& Stein, 2015; Fouquau \& Spieser, 2015; Gandhi, Golez, Jackwerth, \& Plazzi, 2019; Hou \& Skeie, 2014; McConnell, 2013; Yeoh, 2016)). To provide some examples, Snider and Youle (2010) demonstrated that LIBOR did not accurately reflect average bank borrowing costs. They presented evidence that several banks had large portfolio exposures to LIBOR and profited from its rapid descent. In their opinion, these exposures may have been the source of misreporting incentives. Abrantes-Metz et al. (2012) then compared LIBOR with other short-term borrowing rates, analyzed individual bank quotes, and compared these with CDS spreads and market capitalization data during three periods: 1 January $2007-8$ August 2007 (period 1), 9 August 2007 - 16 April 2008 (period 2), and 17 April 2008 - 30 May 2008 (period 3). They found anomalous individual quotes, but inconsistent evidence with a material manipulation of the US dollar 1-month LIBOR rates. Furthermore, Monticini and Thornton (2013) investigated whether the underreporting of LIBOR rates by some banks significantly impacted the published LIBOR rate. They tested whether there was a significant change in the relationship between the LIBOR rate and other rates reflecting the default risk of banks. Finally, Ashton and Christophers (2015) examined arbitrage in financial markets and their governance thereby unpacking LIBOR and the LIBOR scandal. With respect to EURIBOR, the literature is more scarce with only a handful of articles focusing on the influence of ECB policy announcements on its fixing (e.g. (Bernoth \& Hagen, 2004; Shaw, Murphy, \& O’Brien, 2016; Vergote \& Gutiérrez, 2012)) and EURIBOR manipulation (e.g. (Caporale \& Gil-Alana,

\footnotetext{
5(2) of Directive 2014/57/EU of the European Parliament and of the Council of 16 April 2014 on criminal sanctions for market abuse considers transmitting false or misleading information or providing false or misleading inputs or any other behavior which manipulates the calculation of a benchmark as market manipulation. ${ }_{17}$ Regulation (EU) 2016/1011 of the European Parliament and of the Council of 8 June 2016 on indices used as benchmarks in financial instruments and financial contracts or to measure the performance of investment funds and amending Directives 2008/48/EC and 2014/17/EU and Regulation (EU) No 596/2014.
} 
2016; Eisl, Jankowitsch, \& Subrahmanyam, 2017; Ghosh, Le Roux, \& Verma, 2020; Rodriguez-Lopez et al., 2020; Taboga, 2014)). With respect to the latter stream of literature, Caporale and Gil-Alana (2016) documented no persistence in the monthly EURIBOR rates suggesting a non-representative benchmark for the unsecured money market. Eisl et al. (2017) analyzed LIBOR and EURIBOR submissions by the individual banks thereby shedding light on the underlying manipulation potential of these benchmarks. Ghosh et al. (2020) examined five panel banks (i.e. HSBC, ING, Deutsche Bank, National Bank of Greece, and Barclays) from January 2009 to December 2017 and found evidence that EURIBOR could be predicted in all five cases with different degrees because of a profound herd being observed. Rodriguez-Lopez et al. (2020) tested for the existence of manipulation with respect to the 12-month EURIBOR and analyzed the impact on the mortgage market. Their findings suggest that there was a significant negative effect of the manipulative behavior on the mortgage market, with borrowers overpaying on interest. Finally, Taboga (2014) focused on the ambiguous definition of the 'prime bank' concept (see infra). This scholar conducted a survey where the participants were asked at what rate they believed interbank funds to be exchanged between prime banks. He found evidence that some of the variability of the EURIBOR rates could be explained by changes in the survey participants' perceptions of what a prime bank is. Regarding the Euro Overnight Index Average (EONIA), only a handful of studies have focused on the effect of monetary policy decisions of the ECB as well as on the EONIA spread with key ECB policy rates. For instance, Nautz and Offermanns (2007) examined the dynamic relationship between the euro overnight rate, the ECB's policy rate and the term spread. Hassler and Nautz (2008) applied fractional integration techniques to examine the persistence of the spread between the EONIA and the key policy rate. If EONIA indeed signals the monetary policy stance of the European Central bank, the spread should be indeed persistent. Linzert and Schmidt (2011) then examined the spread between EONIA and the ECB's policy rate, while Beirne (2012) focused specifically on the EONIA spread before and during the financial crisis of 2007 and the role of liquidity and credit risk. Picault (2017) examined the ECB's forward guidance with the EONIA swap curve, while Fiszeder and Pietryka (2018) analyzed the monetary policy in steering the EONIA and POLONIA rates in the Eurosystem and Poland. To the best of our knowledge, no article to date discusses the defects related to EONIA, its reform and the actions to transition away from this benchmark.

To the best of our knowledge, this article is the first to provide a holistic overview of the reforms of the EURIBOR and the EONIA, as well as the on-going work to transition away from EONIA towards the Euro shortterm rate $(€ \mathrm{STER})$. Although a handful of articles have touched on the reform of LIBOR (e.g. (Dao, Godwin, \& Ramsay, 2016; Duffie \& Stein, 2015; Perkins \& Mortby, 2015)), none of them discussed in great detail the reform of EURIBOR and EONIA and the findings concerning LIBOR do not necessarily apply in the same way to EURIBOR and EONIA. To date, no article has provided an overview on the alternative fallback rate methodologies in case an IBOR substantially changes or is ceased to be provided. Based on an extensive review of the academic literature and legal literature combined with a screening of news articles and policy papers, this article is the first to describe the efforts that have been made, by the administrator, the panel banks as well as by the FSMA, to reform EURIBOR and to keep it operational, at least in the medium term. Furthermore, it explains the choice of the EU RFR Working Group and the administrator to recalibrate EONIA into €STER + a spread of 8.5 basis points. The article further documents the request of the administrator to have the recalibrated EONIA authorized, but to have EONIA discontinued in the end.

\section{EURIBOR REFORM}

\subsection{Definition of EURIBOR and its Usage}

The EURIBOR benchmark, representing the unsecured borrowing costs of financially sound banks in Euro, is one of the most used benchmarks in the world. According to the FSB, for a notional of 150 to 180 trillion EUR in 
contracts refer to EURIBOR, being mostly loans and debt securities. ${ }^{18}$ In comparison with to other major IBORs, such as LIBOR, EURIBOR is widely used in contracts entered into by consumers and retail investors, like in mortgages. Given its importance, the European Commission consequently designated EURIBOR as a critical benchmark under the BMR on 12 August 2016 ${ }^{19}$. As the administrator of the EURIBOR, EMMI, is based in Brussels, it falls under the supervision of Belgian Financial Services and Markets Authority (FSMA). ${ }^{20}$ As prescribed by the BMR, the FSMA established a supervisory college on 21 September $2016 .{ }^{21}$

EMMI was founded as EURIBOR-EBF in 1999, being a division of the European Banking Federation (EBF), in parallel with the launch of the euro. The administrator became a non-for-profit organization and changed its name to EMMI in 2014. Its general assembly is composed of the national banking associations of EU countries (as full members) and EFTA countries (as associated members).

\subsection{Modification of the Methodology and Authorization of EMMI as a Benchmark Administrator}

Since its creation, EURIBOR used to be calculated with input data based on expert judgement provided by a panel of contributing banks located all over Europe. The submitters for these banks provided quotes that reflected their estimation of the rate at which euro interbank term deposits were being offered within the EU and EFTA countries by one prime bank to another at 11:00 Brussels time. Submitters provided quotes for the different tenors starting from 1 week up to 12 months. Operationally, the submitters of the panel banks assessed various market data sources and made a judgement as to the likely rate at which a prime bank could borrow. Which market data to use was up to the discretion of the individual panel banks. EMMI initially drafted a code of conduct that provided guidance and a data hierarchy concerning the expert judgements of the panel banks but this code of conduct was, before the introduction of the BMR, not based on any hard law.

The concept of a prime bank was not clearly defined and contributors had heterogeneous views of the concept. At the moment of EURIBOR's creation, all contributors were of high financial standing. However, some contributors considered themselves a prime bank and based their quotes on their own transactions, even though their status of prime bank could be called into question, and vice versa. In the same sense, the concept of an 'offered' rate did not explicitly indicate that the benchmark measures the bank's borrowing cost and not its lending rate. Therefore, most panel banks submitted an indication of a borrowing rate but one could not completely rule out that some submitters also provided lending rates. This approach allowed submitters to provide quotes even when the interbank money market's level of liquidity became very low, leading to an expert judgement on an 'imaginary' market rather than on an actual liquid one (Ashton \& Christophers, 2015). The BMR requires administrators to anchor the benchmark in transactions, if available and appropriate. When input data is transaction-based, there is indeed less room for discretion and, as a consequence, for manipulation. The BMR requires the administrator to use

\footnotetext{
${ }^{18}$ See https://www.ecb.europa.eu/paym/initiatives/interest_rate_benchmarks/WG_euro_risk-free_rates/shared/p

df/20180420/2018_04_20_WG_on_euro_RFR_Item_4_1_Quantitative_mapping_exercise_EONIA_Euribor.pdf

${ }^{19}$ See https://eur-lex.europa.eu/legal-content/EN/TXT/PDF/?uri=CELEX:32016R1368\&from=FR

${ }^{20}$ From 2022, ESMA will take over the supervision of EU critical benchmarks and their administrators. See https://www.esma.europa.eu/about-esma/who-weare/esa-review.

${ }^{21}$ The supervisory college includes ESMA, the national competent authorities of the panel banks, and those of Member States for which the EURIBOR presents a systemic character. See https://www.fsma.be/en/news/fsma-chairs-first-meeting-euribor-college. The college has the role to provide a consultative vote in case of authorisation or cessation of a benchmark as well as when the NCA of the administrator would want to compel a) a panel bank to remain in the panel (mandatory contribution) or b) the administrator to continue to administer a critical benchmark (mandatory administration).
} 
a methodology for determining the benchmark that is robust, reliable, rigorous, continuous, and resilient ${ }^{22}$. The quote-based methodology for EURIBOR was not BMR-compliant, as it was not anchored in transactions nor representative. EMMI first reviewed the benchmark methodology to assess whether to base it fully on transactions. This was done with the ECB's help analyzing transaction data from more than 50 credit institutions collected over the period 2012-2013. EMMI took action to clearly define EURIBOR as the rate at which banks of sound financial standing could borrow funds in the EU and EFTA countries in the wholesale, unsecured money market in euro. This definition included wholesale transactions and not only interbank transactions. The reason is that, although bank-to-bank borrowing was the predominant financing source for banks during the 1980 s and 1990 s, it steadily declined and banks started to rely on broader wholesale funding.

A 2016/2017 pre-live verification program showed, however, that a EURIBOR fully based on transactions would not meet de requirements of de BMR. ${ }^{23}$ The daily determination of the index would be based, for most tenors, on a limited number of transactions executed by a limited number of contributors, making the fullytransaction benchmark insufficiently robust. Since the BMR allows other data inputs if the transactional data is not sufficient, EMMI established a task force to examine the development of a hybrid methodology anchored to the largest extent possible in transactions and in compliance with the BMR. ${ }^{24}$ The hybrid methodology seeks to ground the calculation of EURIBOR, to the largest extent possible, in euro money market transactions. Just as was the intention for the fully-transaction based EURIBOR, the latter was explicitly formulated into the rate at which wholesale funds in euro could be obtained by credit institutions ${ }^{25}$ in the EU and EFTA countries in the unsecured money market. The hybrid methodology follows a hierarchical approach consisting of three levels. The methodology first takes into account eligible transactions in the wholesale-unsecured money market at the defined tenor from the prior TARGET day (level 1). Only transactions directly denominated in euro and transactions executed on TARGET day $\mathrm{T}$ are eligible for a level 1 contribution on TARGET day $\mathrm{T}+1$. Furthermore, only transactions with a fixed rate are eligible and floating-rate transactions referenced to the unsecured euro overnight interest rate can be converted to a fixed equivalent by the panel bank. Unsecured cash deposits attracted from deposit-taking corporations (except central banks), money market funds, non-money market funds, other financial intermediaries (except insurance corporations and pension funds), financial auxiliaries, captive financial institutions and money lenders, insurance corporations, pension funds, central banks, and general governments are eligible as well as short-term securities (i.e. commercial paper, European commercial paper, certificates of deposits, etc.). This means that transactions with corporates are not eligible as these are often transactions at non-arms length commercial terms. Intragroup transactions are not eligible, nor borrowings or securities with embedded options.

\footnotetext{
${ }^{22}$ ESMA consulted on draft technical standards for benchmarks further specifying the conditions that ensure that the methodology an administrator uses to determine a benchmark complies with the relevant requirements of the BMR. See https://www.esma.europa.eu/press-news/esma-news/esma-consults-drafttechnical-standards-benchmarks.

${ }^{23}$ See https://www.emmi-benchmarks.eu/assets/files/D0246B-2017_PLVP\%20public\%20report\%20and\%20wa y\%20forward_FINAL.pdf

${ }^{24}$ See https://www.emmi-benchmarks.eu/assets/files/D004A-2019\%20EUribor\%20Hybrid\%20Methodology_2

019_0_12.pdf

${ }^{25}$ Credit institutions as defined in article 4(1)(1) of Regulation (EU) No. 575/2013, being an undertaking whose business is to receive deposits or other repayable funds from the public and to grant credits for its own account.
} 
Individual transactions should have a notional value of at least $20 \mathrm{M} \mathrm{EUR.}{ }^{26}$ EMMI used, to the extent possible, a reporting format similar to the one used by the ECB for the money markets statistical reporting (MMSR). ${ }^{27}$

In case a bank does not have a level 1 transaction for a given tenor on a certain day, EMMI will use a level 2 contribution, if possible. Level 2 consists of contributions based on eligible transactions in the underlying interest across the money market maturity spectrum, using a defined range of formulaic calculation techniques provided by EMMI, such as interpolation between adjacent tenors, the usage of non-standard maturities, and gap-filling. ${ }^{28}$

If this level 2 approach is not possible, and only then, level 3 input data can be provided by banks. Each panel bank individually established its methodology for determining level 3 contributions, allowing it to reflect its particular circumstances and business patterns, funding, and liquidity management. This implies that a contributor retains a certain level of discretion in the choice and design of its level 3 methodology, but always within the general framework defined by EMMI. ${ }^{29}$ EMMI required panel banks to take the following waterfall principle into account when developing their level 3 methodology: a) data grounded in actual transactions, where the transaction reasonably reflects the underlying interest, b) data based on executable quotes, c) indicative prices, rates or quotes, with no firm commitment for execution, and d) data reliant primarily on the expert judgement of a panel bank.

Level 3 data is thus not 'pure' expert judgement but remains in principle based on transactions in the underlying interest that EURIBOR seeks to measure, but that were not eligible, such as small transactions and transactions with corporate counterparties. In case these are not available, banks have to first use transactions of markets closely related to the unsecured money market, such as transactions in the OIS market, forward rate agreements, and futures contracts referring to EURIBOR thereby using a combination of modelling techniques and/or expert judgement. In case the contributor uses expert judgement, it has to describe in detail in EMMI's submission system how the expert judgement was determined. Furthermore, supervised contributors have to adhere to article 16 of the BMR and the code of conduct developed by EMMI. This implies that contributors have to clearly document the specific approaches that they adopt for their level 3 contributions. These have to be reviewed at least annually by an independent risk management or equivalent function within the bank. EMMI itself also reviews the documented policies and performs periodic surveys. The hybrid methodology is applied progressively, meaning that a panel bank's contribution will be determined using the level 1 data when available. If no level 1 data is available, the contributor can submit level 2 data. Only when no level 1 and level 2 contributions are possible, banks are allowed to provide level 3 submissions. This progressive approach does not allow banks to change their level 1 submissions based on their expert judgement because they consider their transactions are not

${ }^{26}$ For more information, see https://www.emmi-benchmarks.eu/assets/files/D0373-2018\%20Second\%20Consu

ltation\%20Hybrid\%20Euribor_full.pdf

${ }_{27}$ Under Regulation (EU) No 1333/2014, the 50 th largest banks in the Eurozone are required to report to the ECB directly, or indirectly via the national central bank of the member state where they are domiciled, daily statistical information related to money market instruments (i.e. unsecured transactions, secured transactions,

FX transactions and overnight index swaps transactions denominated in euro of any maturity and conducted with financial corporations (except central banks where the transactions is not for investment purposes), general government or non-financial corporations classified as 'wholesale' according to the Basel III LCR framework.

${ }^{28}$ More specifically, Level 2.1 uses linear interpolation from the two adjacent tenors where there is a L1 contribution on a particular day. The linear interpolation is then submitted to a spread-adjustment reflecting the curvature of the EURIBOR curve. Level 2.2 uses transactions with a maturity falling on a non-defined tenor. These transactions are split into the two nearest tenors using linear interpolation. Finally, Level 2.3 uses historical L1 contributions from the previous 4 days and adjusts the historical contribution rate with a market adjustment factor derived from changes in the prices of 3-month EURIBOR futures. For more information, see https://www.emmi-benchmarks.eu/assets/files/Do016A-2019\%20Benchmark\%20Determination\%20Method ology\%20for\%20EURIBOR.pdf

${ }^{29}$ See https://www.emmi-benchmarks.eu/assets/files/D0246A-2019-EURIBOR\%20Benchmark\%20Statement

FINAL.pdf 
representative for the whole market. Once EMMI receives all panel bank submissions, EURIBOR is calculated as the $15 \%$ trimmed average of the individual panel bank contributions, being level 1, level 2 , or level 3 submissions depending on the available transactions. EMMI gradually implemented the hybrid methodology between April and November 2019. Panel banks gradually phased-in to provide for a smooth transition from the quote-based to the hybrid methodology. This was preferred over a one-time shift to minimize operational and technological risks for panel banks, users, and the benchmark itself. ${ }^{30}$ EMMI randomly determined the order in which panel banks phasedin. Figure 1 displays the evolution of EURIBOR 3M, focusing on the transition period in 2019, where the effects of the phase-in are displayed on the left-hand side and the long-term EURIBOR $3 \mathrm{M}$ rate development on the righthand side. The EURIBOR first steadily decreased during the phase-in starting in May 2019 as the hybrid methodology better represents the wholesale borrowing rate of panel banks than the quote-based EURIBOR based only on inter-bank transactions. Following the decision of the ECB's governing council in September 2019 to decrease the interest rates on the deposit facility by 10 basis points to $-0.50 \%{ }^{31}$, EURIBOR increased slowly. When comparing the evolutions with the long-term EURIBOR 3M rate development, the impact on the EURIBOR changes due to the phase-in was minor. To guarantee further transparency, EMMI publishes anonymized indicators, such as a) an indication of the reliance on each of the different levels of the new methodology, b) aggregated volumes underpinning the benchmark's determination, and c) the percentage of counterparty types in level 1 submissions. EMMI publishes these indicators monthly with a delay of one month. ${ }^{32}$

\section{Graph Euribor rate development in 2019}

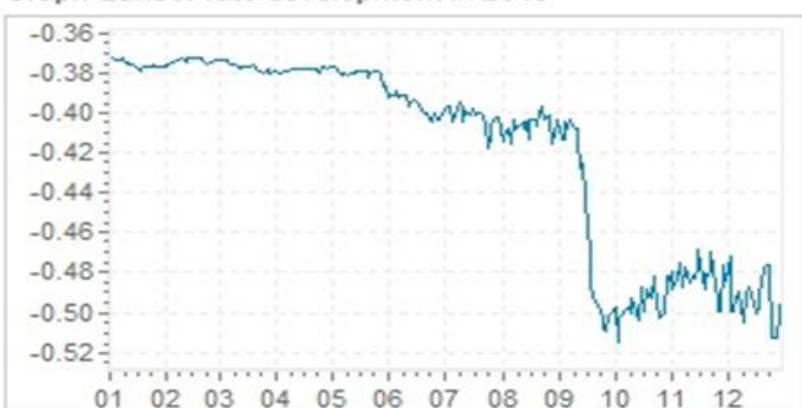

\section{Graph of long-term Euribor rate development}

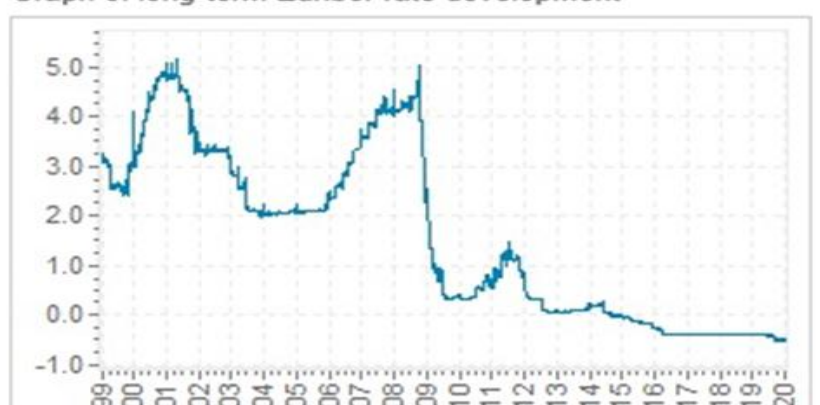

Figure-1. Development of the EURIBOR

Note: EURIBOR 3M evolution where the effects of the phase-in towards the hybrid methodology are displayed on the left hand side and the long-term EURIBOR 3M rate development on the right-hand size. The Y-axis denotes the rate, while the X-axis the month in 2019 (left hand size) or the year (right hand side). Source = global-rates.com.

On 6 May 2019, EMMI announced that it had, besides starting transitioning from the quote-based EURIBOR to the hybrid one, applied for authorisation under the BMR. ${ }^{33}$ The FSMA, after consulting the college of supervisors, finally granted the authorisation to EMMI for the EURIBOR benchmark on 2 July $2019 .{ }^{34}$ EMMI

\footnotetext{
${ }^{30}$ According to EMMI, EURIBOR under the hybrid methodology continues to measure the same underlying interest as EURIBOR calculated under its legacy methodology. (see https://www.ecb.europa.eu/paym/

initiatives/interest_rate_benchmarks/WG_euro_risk-free_rates/shared/pdf/20191016/2019-10-16_WG_on_eu

ro_RFR_meeting_Frequently_Asked_Questions.pdf) and https://www.emmi-benchmarks.eu/assets/files/Do0

62A-2019\%20-20Euribor\%20Questions\%20and\%Answers.pdf. The same conclusions hold for the reformed EONIA (see infra).

${ }^{31}$ See https://www.ecb.europa.eu/press/pr/date/2019/html/ecb.mp190912 08de50b4d2.en.html.

${ }^{32}$ See https://www.emmi-benchmarks.eu/euribor-org/about-euribor.html.

${ }^{33}$ See https://www.emmi-benchmarks.eu/assets/files/D0062A-2019\%20-\%20Euribor\%20Questions\%20and\%A

nswers.pdf

${ }^{34}$ See https://www.fsma.be/en/news/fsma-authorises-emmi-administrator-euribor-benchmark. See also the speech by Steven Maijoor (European Securities and Markets Authority) on 25 September (https://www.esma.europa.eu/sites/default/files/library/esma71-319-141_speech_esma_chair_roundtable_eur
} 
thereby fulfils the requirements of the BMR and EURIBOR, being considered as a robust and representative benchmark, can be used in legacy as well as new contracts for the foreseeable future.

\subsection{Panel Stability}

Under the hybrid methodology, panel banks and their input data remain an indispensable part of the determination process of EURIBOR. To ensure the robustness and accuracy of the benchmark, the administrator should take the necessary measures to ensure that the panel remains reliable and representative. In 2012, 44 banks were part of the panel. Over time this progressively shrunk to 18 banks. Contributing to a benchmark indeed remains a voluntary activity but has the consequence that, as a panel bank, you need to follow numerous requirements. In addition, every bank can use the benchmark while only a limited number of contributors bear these costs, creating incentives for a true free-riding problem. A further decline, however, does not appear advisable. To assure panel stability and thus also representativeness of a critical benchmark, the BMR grants the national competent authority of the administrator the power to require supervised entities, including entities that are not yet contributors to the benchmark, to (continue to) contribute input data per the administrator's methodology and its code of conduct. Contributors that cease to contribute input data can namely undermine the benchmark's credibility, as the capability of the benchmark to measure the underlying economic reality may be impaired because of their withdrawal from the panel. The mandatory contribution requirement is, however, limited in time.

\subsection{Future of the EURIBOR?}

Andrew Bailey, at the time CEO of the UK's Financial Conduct Authority, raised serious concerns about the sustainability of LIBOR. He stated that, after 2021, the FCA would no longer persuade or compel banks to submit input data. ${ }^{35}$ Since November 2017, the FCA had an agreement with the panel banks to further sustain LIBOR until the end of $2021 .{ }^{36}$ Andrew Baily announced that authorities in the UK would take steps to ensure that supervised companies produce adequate plans to mitigate their dependencies on LIBOR. ${ }^{37}$ Even the COVID-19 pandemic would not lead to a further extension of sustaining LIBOR. ${ }^{38}$ Similar messages were given by Bill Dudley, CEO of the Federal Reserve Bank of New York ${ }^{39}$, Mark Carney, former governor of the Bank of England, ${ }^{40}$ and Chris Giancarlo, Chairman of the Commodity Futures Trading Commission. ${ }^{41}$ As the future of the IBORs was uncertain, various working groups on the developments of risk-free rates were established, such as the Sterling Working Group in the UK and the Alternative Reference Rates Committee (ARCC) in the USA.

Regarding EURIBOR, Jean-Paul Servais stressed that under the hybrid methodology the benchmark is here to stay, at least in the medium term. ${ }^{42}$ The EU RFR Working Group (see infra) also did not get a mandate to look for

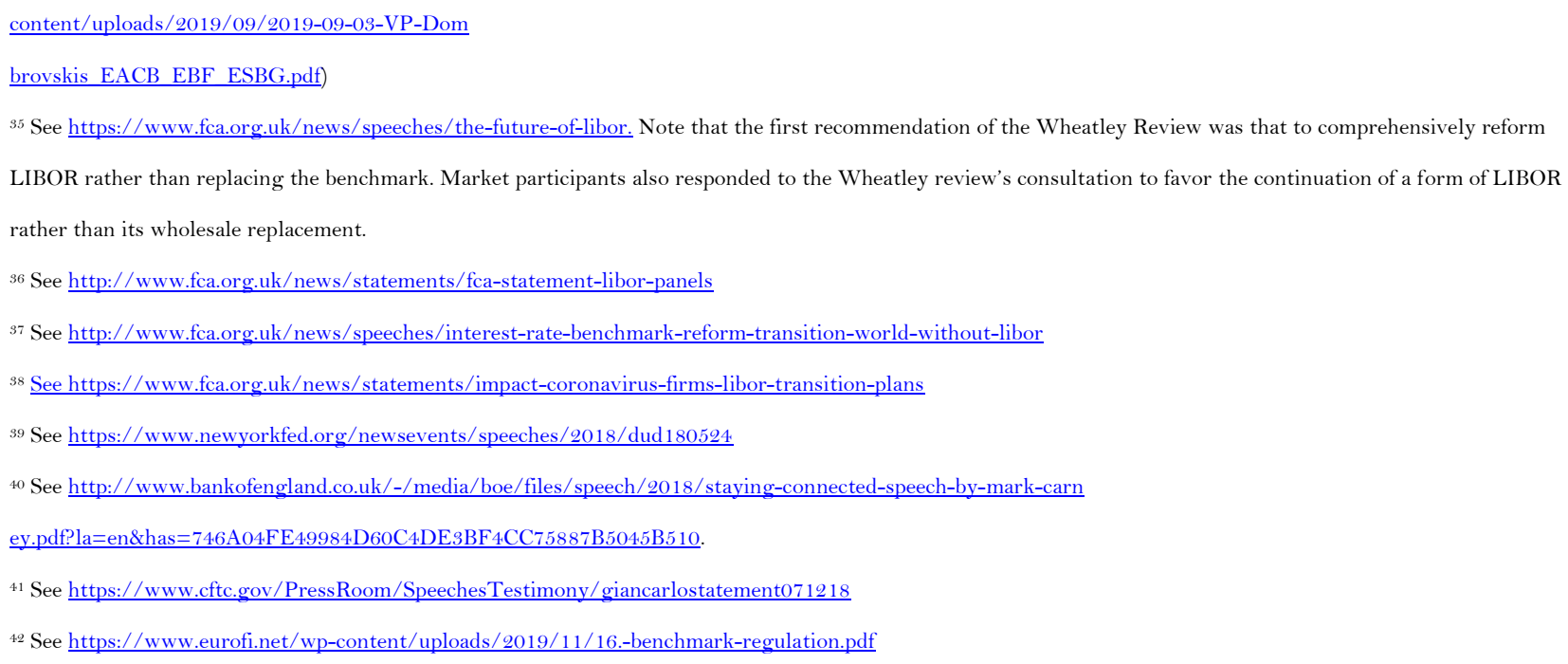


replacement rates for EURIBOR but only to create fallback rates that could be used e.g. in parallel to EURIBOR. This approach is in line with FSB's multi-rate approach preference. During the COVID-19 crisis between March and May 2020, the EURIBOR increased, as expected in light of the market uncertainty. The benchmark remained robust with a daily fixing and representative rates correlating with $€$ STER and Euro LIBOR ${ }^{43}$.

\section{EONIA REFORM}

\subsection{Definition of EONIA and its Usage}

The underlying interest that EONIA measures is the rate at which banks of sound financial standing in the European Union (EU) and European Free Trade Association (EFTA) countries lend funds in the overnight, interbank money market in euro. EONIA, published by EMMI since 1999, was designated as a critical benchmark by European Commission in June 2017.44 EONIA is one of the most important benchmarks in the banking and short-term investment sector and market participants use it in a wide range of products and instruments. At the time of designation, EONIA was used for about EUR 5.2 trillion in the EONIA swap market (i.e. mainly OIS) and for EUR 850 billion in money market instruments. ${ }^{45}$ Historically, this benchmark has been used especially by financial counterparties, such as banks, asset managers, pension funds, and corporate investors for margin and collateral calculations, risk management purposes, and for financial and hedge accounting purposes.

\subsection{Modification of the Methodology}

Until 2 October 2019, EONIA was calculated based on daily contributions by 28 contributors from 13 EUcountries. The benchmark was computed as the volume-weighted average of all panel banks' submissions. The input data consisted of real overnight lending rate transactions. The benchmark was thus directly anchored in the cash market and based on real transactions. Being a transaction-based benchmark, the market considered it as less vulnerable to potential manipulation. At the end of 2015, EMMI started the review of EONIA to enhance the governance and control framework and assess the robustness and representativity of the methodology. In April 2017, EMMI invited all contributors to participate in the Review Data Exercise and report their euro-denominated lending transactions over a 6-month period. EMMI detected that the panel, based on their interbank unsecured lending transactions, was too concentrated and thus not BMR compliant. Given the index' concentration, a single panel bank would have been able to affect the benchmark by executing transactions. Furthermore, the volumes in the underlying overnight market that EONIA measures occasionally reached historically low values in 2017.

The low levels of activity in the underlying market and the limited number of active participants in the lending market led to the conclusion that even enlarging the number of contributing banks would not solve the issue. Therefore, EMMI could not apply for authorisation for EONIA under the BMR. Furthermore, panel banks and market associations considered the ECB to be better positioned to create a more robust (overnight) benchmark that could serve as an RFR for EURIBOR. Also in the UK and the USA, the Bank of England publish SONIA and the Federal Reserve publish SOFR. ${ }^{46}$ The ECB indeed collects money market statistical information from a larger number of banks, which could be directly used to calculate the benchmark (see infra).

\footnotetext{
${ }^{43}$ See https://www.euribor-rates.eu/en/current-euribor-rates/2/euribor-rate-3-months/

${ }^{44}$ See https://eur-lex.europa.eu/legal-content/EN/TXT/?uri=celex:32017R1147

${ }^{45}$ See https://www.ecb.europa.eu/paym/initiatives/interest_rate_benchmarks/WG_euro_risk-free_rates/shared/p

df/20180226/Item_3_3.pdf

${ }^{46}$ In 2013, EMMI and the European Repo Council launched a Secured Benchmark Indices Joint Task Force to explore the feasibility of a transaction-based repo benchmark. This task force decided at the end of 2014 that a transaction-based repo benchmark was achievable. In 2015 and 2016 , EMMI analyzed whether the data captured by three of the most active Automatic Trading Systems (ATS) in Europe were sufficient and which design considerations needed to be taken into account.
} 
In February 2018, the ECB, ESMA, FSMA, and the European Commission established the EU RFR working group; an industry-led group of credit institutions. ${ }^{47}$ Its main tasks are to identify and recommend alternative riskfree rates and transition paths. ${ }^{48}$ On 13 September 2018, the EU Working Group recommended the Euro shortterm rate $(€ \mathrm{STER})$ as an alternative risk-free rate to replace EONIA. ${ }^{49}$ Based on various criteria, such as the compliance with the IOSCO Principles for Financial Benchmarks and the liquidity in the underlying market, the working group selected this benchmark over the GC Pooling Deferred (i.e. a one-day secured, centrally cleared, general collateral repo rate produced by STOXX) and the RepoFunds Rate (i.e. a one-day secured, centrally cleared, combined general and specific collateral repo rate produced by NEX Data Services Limited). The ECB developed a methodology based on the information from the 50 largest banks in the Eurozone, who report to the ECB under the MMSR Regulation. The ECB calculates €STER as the weighted average of the individual transactions in the European monetary market on a daily basis. The rate captures interbank transactions but also interests paid by banks on deposits from other counterparties, such as pension funds and investment companies. €STER thus reflects the wholesale euro unsecured overnight borrowing cost of euro area banks. Only overnight unsecured fixed-rate deposit transactions over EUR 1 million are taken into consideration. €STER had the first fixing of -0.549 percent based on transactions from 32 active banks who had 432 actual transactions. To provide market participants sufficient time to transition from EONIA to $€ \mathrm{STER}$, the RFR working group, in cooperation with EMMI, preferred to keep EONIA alive for a limited period until the end of 2021. To facilitate the transition, the RFR working group also recommended on 14 March 2019 a modification of EONIA's methodology. ${ }^{50}$ EMMI was advised to a) modify the methodology to become $€$ STER plus a spread, b) engage with the relevant authorities to ensure the compliance of EONIA, under its evolved methodology, with the BMR, and c) consider and consult market participants on discontinuing the publication of EONIA under its evolved methodology after a transition period that ensures firms can smoothly achieve a transition to $€$ STER. The spread between EONIA being a lending rate and $€$ STER being a borrowing rate was fixed by the ECB at 8.5 basis points based on daily EONIA and pre-€STER data from 17 April 2018 to 16 April 2019. ${ }^{51}$ The main advantage of the predetermined and constant spread is that it smoothens out perceived valuation transfers and balance sheet impacts, thus lowering the barriers to subsequently transition away from EONIA towards €STER. To further support the transition from EONIA to €STER, the EU RFR working group published a report on the impact of the transition from EONIA to $€$ STER on cash products (e.g. mortgages,

\footnotetext{
Data was provided by BrokerTec, MTS, and Eurex, spanning 10 years of repo activity from 2006 to 2015 . The analysis was delivered by the University of St. Gallen in November 2015. Yet, this project was stopped in 2018.

${ }^{47}$ See https://www.ecb.europa.eu/paym/initiatives/interest_rate_benchmarks/WG_euro_risk-free_rates/shared/p

df/2017_11_29_terms_of_reference.pdf

${ }^{48}$ Similar initiatives had also been taken to deal with the transition of the LIBOR. For instance in the USA, the Alternative Reference Rates Committee (ARRC) was already founded in November 2014 to transition away from US Libor to the Secured Overnight Finance Rate (SOFR) published by the Federal Reserve Bank of New York. The ARRC consists of representatives from large global interest rate derivatives dealers, the Federal Reserve, and the US Treasury participating as ex officio members. In the UK, The Working Group on Sterling Risk-free rates was founded in March 2015 and was tasked with the transition from GDP Libor to the reformed Sterling Overnight Index Average (SONIA) published by the Bank of England. This Working Group is comprised of senior subject matter experts from major sterling swap dealers, ISDA, and representatives from the Bank of England and the FCA as ex officio members. Also in Switzerland, the National Working Group on Swiss Franc Reference Rate, founded in 2013, looked into the transition of the CHF Libor to the Swiss Average Rate Overnight (SARON) published by the Six Exchange.

${ }^{49}$ See https://www.ecb.europa.eu/pub/pdf/annex/ecb.sp190314_annex_recommendation.en.pdf

${ }^{50}$ See https://www.ecb.europa.eu/press/pr/date/2019/html/ecb.pr 190531 a3788de8f8.en.html

${ }^{51}$ See https://www.ecb.europa.eu/paym/initiatives/interest_rate_benchmarks/WG_euro_risk-free_rates/shared/p

df/20181219/2018-12-19_WG_on_euro_RFR_meeting_Item_3_Update_by_subgroup_4_on_EONIA_transi

tion.pdf
} 
loans, and bonds) and derivatives (e.g. swaps and futures). ${ }^{52}$ The report analyzes the implications for those financial products and provides market participants with operational recommendations on how to smoothen the transition. ${ }^{53}$ Discussions were also held with central counterparties for them to assist in establishing liquid €STER derivatives markets. The Working Group recommended CCPs to implement a discounting / price alignment interest (PAI) switch towards the summer of 2020. ${ }^{54}$ Furthermore, the working group analyzed e.g. the impact for accounting ${ }^{55}$ and risk management. ${ }^{56}$ On 20 March 2019 EMMI launched a consultation on the change in the methodology of EONIA. ${ }^{57}$ Following the consultation, EMMI decided to continue to publish EONIA under the legacy methodology until the ECB started publishing €STER on 2 October 2019. The publication of EONIA under the old methodology moved from the evening on time ' $\mathrm{T}$ ' (i.e. 19:00 CET) to ' $\mathrm{T}+1$ ' (i.e. 9.15 CET) under the new recalibrated methodology to be aligned with the €STER publication on time $\mathrm{T}+1$ (i.e. 8:00 CET). Figure 2 displays the evolution of EONIA where the effects of the recalibration to $€$ STER are displayed on the left-hand side and the long-term EONIA development on the right-hand side. The large drop in September 2019 is due to the monetary decisions of the European Central Bank. The impact of the recalibration itself only led to a small drop, being almost invisible on the charts.
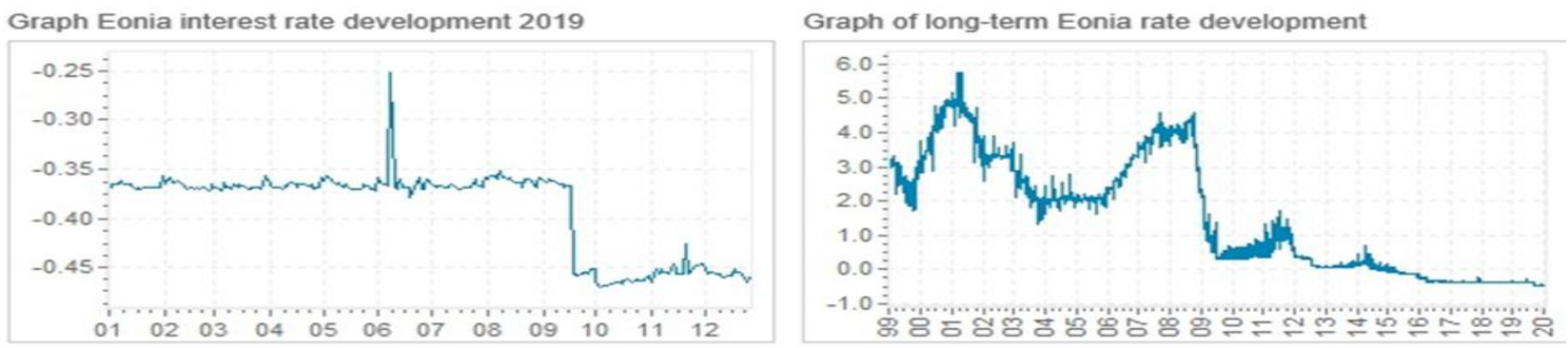

Figure-2. Development of EONIA.

Note: EONIA evolution where the effects of the recalibration to €STER are displayed on the left-hand side and the long-term EONIA rate development on the righthand size. The Y-axis denotes the rate, while the X-axis the month in 2019 (left hand size) or the year (right hand side). Source = global-rates.com.

\footnotetext{
${ }^{52}$ See https://www.ecb.europa.eu/pub/pdf/other/ecb.wgeurorfr_impacttransitioneoniaeurostrcashderivativespro ducts $\sim$ d 917 dffb84.en.pdf

${ }_{53}$ Also the European Repo and Collateral Council (ERCC) of the International Capital Market Association (ICMA) published recommendations for the repo market. One of the recommendations is that the interbank market should transact on a fixed-rate basis (i.e. classic repos) and should stop using floating rate repos, which was already the minority of the number of transactions (see https://www.icmagroup.org/news/news-in-brief/icma-ercc-published-updated-memorandum-outliningrecommendations-for-repo-market-best-practice-to-address-transition-from-eonia-to-str-on-1-october-2019).

${ }^{54}$ For instance LCH. Clearnet Ltd communicated on 27 September 2019 that it would transition to €STER for the discounting in SwapClear. Clear discounting is used for cleared derivatives (i.e. a single discounting curve is used), a cash compensation payment is applied for all accounts with a live euro-denominated position at the point of conversion (see https://www.lch.com/membership/ltd-membership/ltd-member-updates/transition-eustr-discounting-swapclear). LCH. Clearnet Ltd was also the first CCP to start clearing euro interest rate swaps referring to €STER, where Morgan Stanley and Landesbank Baden-Württemberg Bank were amongst the first to clear derivatives referencing to €STER on 2 October 2019 (see http://www.sec
} uritieslendingtimes.com/securitieslendingnews/swaparticle.php?article_id=223430). On the same day that €STER became available, BBVA completed its first

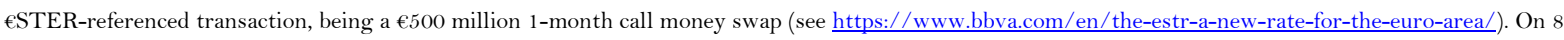
October 2019, Bloomberg announced that the first electronically negotiated euro short-term rate (€STER) swap transaction was executed on its UK MTF, operated by Bloomberg Trading Facility Limited (see https://www.bloomberg.com/company/press/first-fully-electronic-estr-swap-trade-executed-via-bloombergs-uk-mtf/).

${ }^{55}$ See https://www.ecb.europa.eu/pub/pdf/other/ecb.wgeurofr_financialaccountingimplicationstransitioneoniae urostrfallbackseuribor 6e1bb63340.en.pdf

${ }^{56}$ See https://www.ecb.europa.eu/pub/pdf/other/ecb.wgeurofr_riskmanagementimplicationstransitioneoniaeuros trfallbackseuribor $\sim 156067$ d893.en.pdf ${ }^{57}$ See https://www.emmi-benchmarks.eu/assets/files/Doo88-2019\%20Eonia\%20consltaiton\%20FRF\%20WG .pdf 


\subsection{The Authorization for EONIA}

Given the systemic importance of EONIA, EMMI decided to file for authorisation for this benchmark. After consulting the college, the FSMA decided in December 2019 to extend the authorisation of EMMI as an administrator for EURIBOR to include EONIA. ${ }^{58}$ As the continued use of EONIA under the recalibrated methodology is only intended as a temporary solution to facilitate the transition to $€ \mathrm{STER}$, EMMI consulted and informed the market that EONIA will be discontinued on 3 January 2022.59 This means that both EONIA and €STER run in parallel for about two years and the market should use this period to move all their contracts, systems, and valuation rules to $€ \mathrm{STER}$.

In light of the end date for EONIA, the EU working group identified the importance of clear communication to and education of market participants. ${ }^{60}$ Market participants should be made aware of the risks in continuing to reference EONIA in contracts with maturities beyond this date. They should also undertake effective actions to review their contracts, assessing both the fallback language that either is currently used or, in case there isn't any, introduce fallback clauses to minimize legal and economic risks. On 1 July 2020, the FSB repeated its view that, even in a COVID-19 situation, firms should continue to transition to RFRs and in particular remove remaining dependencies on LIBOR by the end of $2021 .{ }^{61}$

\section{FALLBACK RATES}

\subsection{Fallback Provisions}

The BMR requires supervised entities that are benchmark users to have robust written plans setting out the actions they would take in case the benchmark materially changes or ceases to exist. These robust written plans have to, where feasible and appropriate, nominate one or several alternative benchmarks. Fallbacks thus serve as some sort of insurance against the cessation of the benchmark rate and alleviate potential disputes of contracting parties in response to the unavailability of the referenced benchmark rate. The alternative benchmarks that serve as a fallback might, depending on the contractual language, be triggered by a temporary event or be permanent. ${ }^{62}$

On 21 January 2019, the EU RFR working group published a set of guiding principles for fallback provisions in new contracts for euro-denominated cash products covering both EURIBOR and EONIA. ${ }^{63}$ The goal is to reduce legal uncertainty and assist the market in having robust fallbacks in case EONIA disappears and EURIBOR would cease to be published. In July 2019, the working group published recommendations to further facilitate the transition from EONIA to $€ S T E R .{ }^{64}$ An important recommendation was that new contracts and contracts still

\footnotetext{
${ }^{58}$ See https://www.fsma.be/en/news/fsma-authorises-emmi-administrator-eonia-benchmark.

${ }_{59}$ See https://www.emmi-benchmarks.eu/assets/files/D0142-2019\%20Feedback\%20Eonia\%20consultation\%20

$\underline{\text { FRF\%20WG_final.pdf }}$

${ }^{60}$ See https://www.ecb.europa.eu/paym/initiatives/interest_rate_benchmarks/WG_euro_risk-free_rates/shared/p

df/WG_on_euro_RFR_ToR_SG7_on_communication_and_education.pdf

${ }^{61}$ See https://www.fsb.org/2020/07/fsb-statement-on-the-impact-of-covid-19-on-global-benchmark-reform/

${ }^{62}$ A permanent cessation can be a public statement by or on behalf of the administrator announcing that it has ceased or will cease to provide the benchmark

permanently or indefinitely, provided that, at the time of the statement, there is no successor administrator that will continue to provide the benchmark. Another example is of a permanent cessation trigger is a public statement by e.g. the regulatory of the administrator or an insolvency official or central bank for the currency of the benchmark stating that the administrator of the benchmark has ceased or will cease to provide the benchmark permanently or indefinitely, provided that, at the time of the statement, there is no successor administrator that will continue to provide the benchmark. Especially for LIBOR, pre-cessation triggers also exist in case the FCA publicly states that LIBOR is no longer representative. See https://www.fca.org/uk/markets/transition-libor/libor-contractual-triggers.

${ }_{63}$ See https://www.ecb.europa.eu/pub/pdf/other/ecb.sg3guidingprinciples201901.en.pdf

${ }^{64}$ See https://www.ecb.europa.eu/paym/pdf/cons/euro_risk-free_rates/ecb.eurostr_eonia_legal_action_plan_201

90716.en.pdf
} 
referencing EONIA should use $€ \mathrm{STER}$ and the spread of 8.5 basis points as fallback rate. It is, however, recommended that EONIA is no longer used in new contracts and €STER is utilized as much as possible.

On 6 November 2019, the working group published recommendations for fallback provisions in contracts for EURIBOR-referring cash products and derivatives transactions. ${ }^{65}$ In this document, the working group offers an overview of the legal frameworks and market practices that apply to various asset classes, such as consumer loans, bonds, and derivative products, and promotes the usage of effective fallback provisions in contracts for eurodenominated cash products. The working group recommended that all market participants consider incorporating fallback provisions in all new financial instruments and contracts referencing EURIBOR, regardless of whether they fall within the scope of the BMR. On 19 February 2020, the RFR WG published a report on the transfer of EONIA's cash and derivatives markets liquidity to $€$ STER. ${ }^{66}$ This report aims to assist the market in the smooth transition from EONIA to $€$ STER by describing how the market can ensure a liquid $€$ STER cash and derivatives products market. A liquid €STER derivatives market is a precondition for forward-looking term structure methodologies, which might be necessary for the implementation of EURIBOR fallbacks (see infra). Where this report focuses on cash and derivatives products, the working group published on 16 June 2020 a recommendation specifically targeted at swaptions being affected by central clearing counterparties (CCPs)' discounting transition from EONIA to $€ \mathrm{STER} .{ }^{67}$ As the BMR requests the European Commission to review the BMR in 2020, they launched a proposal on 11 October 2019 proposing changes to e.g. the mandatory contribution powers of national competent authorities, the ESMA register of administrator and benchmarks and benchmark statements. ${ }^{68}$ Because of the likely cessation of LIBOR after the end of 2021 and the many legacy financial contracts that reference LIBOR not having fallback provisions, the European Commission published another BMR review proposal on 28 July 2020. ${ }^{69}$ The current proposal grants the European Commission powers to designate a statutory replacement rate that would replace the reference to the benchmark in cessation where a) the contract contains no fallback rate and b) the cessation of the benchmark would result in significant disruption in the functioning of financial markets in the Union for contracts containing no fallback rate. The statutory replacement rate is likely to be the RFR recommended by the risk-free rate working groups potentially added with a term and credit risk component (see infra).

\subsection{Fallback Methodologies}

The EU RFR working group worked considerably on establishing possible fallback arrangements for EURIBOR. RFRs are mostly overnight rates that do not reflect any significant term- and credit risk element. Indeed, an overnight rate in itself cannot simply serve as a fallback for EURIBOR, because the latter is a forwardlooking term rate in the sense that it is set at the beginning of a term period (i.e. $1 \mathrm{~W}, 3 \mathrm{M}, 6 \mathrm{M}$, and $12 \mathrm{M}$ ) and thus incorporates expectations for overnight rates over that specific period. An overnight RFR, in contrast, is backwardlooking reflecting historical rates. Due to the absence of a term premium, it does not compensate lenders for making longer-term funds available and thus for interest rate uncertainty (Acharya \& Skeie, 2011; McAndrews,

\footnotetext{
${ }^{65}$ See https://www.ecb.europa.eu/pub/pdf/other/ecb.wgeurofr_highlevelrecommendatioseuriborfallbacks $\sim$ abc6c

a6268.en.pdf

${ }^{66}$ See https://www.ecb.europa.eu/pub/pdf/other/ecb.wgeurofr_transferofliquidityfromEONIA_scashandderivati

vesmarketstotheeuroshorttermrate $\sim 62$ c9819a5.en.pdf

${ }^{67}$ See https://www.ecb.europa.eu/pub/pdf/other/ecb.recommendation_swaptions_impacted_by_discounting_sw

itch_to_EuroSTR a64fo42ed9.en.pdf?be826ce2fof $27 \mathrm{c} 70 \mathrm{fd} 252 \mathrm{~d} 2 \mathrm{e} 2 \mathrm{cc} 5483 \mathrm{a}$

${ }^{68} \mathrm{See}$ https://ec.europa.eu/info/sites/info/files/business_economy_euro/banking_and_finance/documents/2019-benchmark-review-consultation-document_en.pdf

${ }^{69}$ See https://ec.europa.eu/info/law/better-regulation/have-your-say/initiatives/12268-Review-of-the-Benchmar

k-Regulation-
} 
Ansani, \& Zhenyu, 2008; Michaud \& Upper, 2008). Furthermore, EURIBOR includes term bank credit risk, where RFRs are near risk-free. For this reason, current RFRs, like €STER, have a lower rate than their EURIBOR equivalent. An appropriate fallback for EURIBOR thus needs to include both the term risk and credit risk component. Replacing EURIBOR with an RFR without taking term and credit risk into account would potentially leave a pricing gap which would then require some sort of reimbursement mechanism (Schrimpf \& Sushko, 2019).

The working group discussed both backward-looking fallback rates for EURIBOR, which are based on mathematical calculations on realized daily fixings of the overnight RFR (being backward overnight rates) over a given period in times, as well as forward-looking fallback rates. The working group first recommended that an OIS (tradable) quotes-based methodology would be used to calculate a €STER-based forward-looking term structure.70 A forward-looking benchmark by definition provides more certainty of future funding costs in contrast to backward-looking benchmarks reflecting historical funding costs. This term RFR could then function as a first step to create a fallback for EURIBOR (although at that stage the credit risk component is not yet taken into consideration). The construction of such a term rate has as an advantage that it is transparent as OIS swaps are traded on multilateral trading facilities. However, as it will take some time to develop liquid €STER derivatives markets and thus to have sufficient data on these derivatives, there are currently no forward-looking term rates based on $€ S T E R$ available. This implies that until the liquidity in the €STER derivatives market is substantial, forward-looking term structure methodologies as fallbacks for EURIBOR will be difficult to implement. The working group therefore further examined backward-looking approaches based on the compounding of €STER in arrears. ${ }^{71}$ They could benefit further on the work that the FSB and ISDA have done on this matter. ${ }^{72}$ Figure 3 displays a simplified figure on the difference between back-ward looking and forward-looking term rates where the formula denotes the compounding in arrears methodology ${ }^{73}$ :

\footnotetext{
70 See https://www.ecb.europa.eu/paym/pdf/cons/euro_risk-free_rates/ecb.consultation_details_201812.en.pdf and see https://www.ecb.europa.eu/press/pr/date/2019/html/ecb.pr190314_1 af10eb740e.en.html. Specifically, this methodology uses the mid-price for OIS quotes obtained from regulated electronic trading venues, like MTFs. The benchmark administrator could combine multiple individual central limit order books (CLOBs) across MTFs relevant for the $€$ STER OIS derivative market to capture the maximum possible measure of liquidity. The benchmark administrator could then create a theoretical order book, on which a fixing rate bid and ask could be calculated, based on the weighted average volume. Finally, an averaging process could be used to calculate the final fixing.

${ }^{71}$ Other possibilities are the spot overnight rate approach, where the fallback is the RFR that sets on the date that is one or two business days before the beginning of the relevant IBOR tenor, and the convexity-adjusted overnight rate approach which is similar to the spot overnight rate approach with a first-order modification to adjust for convexity. As an alternative to the compounded setting in arrears rate approach, also the compounded setting in advance rate approach exists which is mathematically the same but where the observation period would end immediately before the start of the relevant IBOR tenor so that the rate would be available at the beginning of the period (Henrard, 2019).

${ }^{72}$ See https://www.fsb.org/wp-content/uploads/P120718.pdf For all consultations of ISDA on this matter, see https://www.isda.org/2019/07/24/benchmarkfallbacks-consultations.

${ }^{73}$ For the backward-looking approach, we do not distinguish between the various alternatives in terms of the observation period to calculate the RFR, the period to calculate the adjustment payment, and the period for which an interest installment is paid. For more information on the various cases (e.g. payment delay, lockout, period, lookback, last reset, last recent, principal adjustment and interest rollover), see https://www.fsb.org/wp-content/uploads/P040619-1.pdf
} 


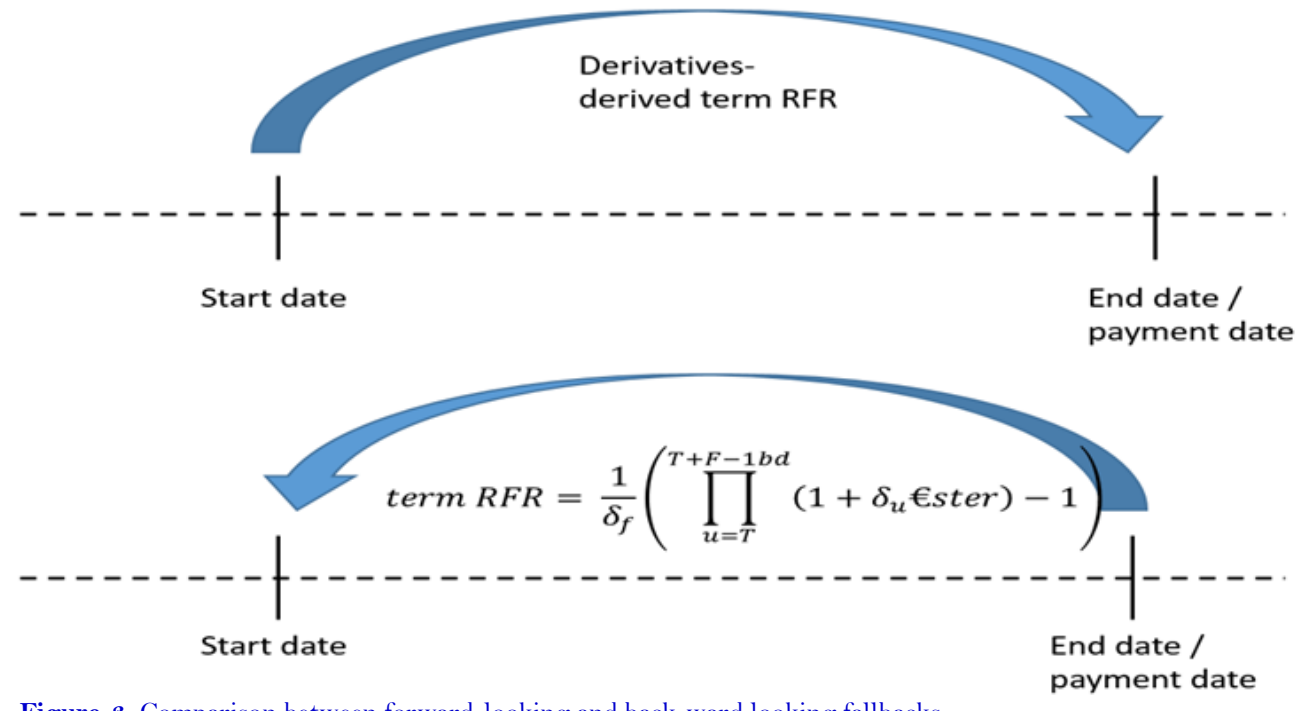

Figure-3. Comparison between forward-looking and back-ward looking fallbacks.

Note: Comparison of the forward and backward-looking methodologies. $T$ denotes the start of the accrual period. The time interval $f$ is the length of the term (i.e. the maturity, like $1 \mathrm{w}, 1 \mathrm{~m}$, etc.). The accrual end date is denoted by T+F. $t$ denotes the setting date for the term RFR, which is assumed to be two business days ("bs")

before the start date (i.e. $\mathrm{t}=\mathrm{T}-2 \mathrm{bds}$ ). $\delta_{f}$ is the cash day count fraction for the accrual period and $\delta_{\mathcal{u}}$ denotes the cash day count fraction for the overnight accrual period from $\mathrm{u}$ to $\mathrm{u}+\mathrm{bd}$.

Although backward-looking methodologies in arrears have the disadvantage that they do not determine the final cash amount until the end of the period until all historical rates are available, an advantage of them is that they are easier to understand and construct. This methodology indeed involves the usage of the overnight RFR compounded over the maturity period the benchmark wants to measure (e.g. 3 months) with the rate only known at the end of that period. On 24 July 2020, the ECB launched a public consultation on the publication of compounded $€ S T E R$ rates. The publication would take place on a daily basis shortly after the $€$ STER publication, for maturities ranging from one week up to one year. ${ }^{74}$ The working group further analyzed how to build a credit risk spread to add to €STER. The work done by ISDA (i.e. historical mean/ median approach) could be useful for market participants in choosing such a credit risk spread methodology. ${ }^{75}$ The working group already launched a call to benchmark administrators for the expressions of interest in producing an €STER-based forward-looking term structure but no administrator is yet authorized for such a benchmark.

\section{CONCLUSION}

Based on an extensive review of the academic and legal literature combined with a screening of news articles and policy papers, this article provides an overview of the EURIBOR and EONIA reforms as well as the on-going work to transition away from EONIA towards €STER. The article describes the efforts that have been made to reform EURIBOR and keep the benchmark operational for the foreseeable future. Furthermore, it explains the choice to recalibrate EONIA into $€ \mathrm{STER}+$ a spread of 8.5 basis points. Although both EURIBOR and EONIA are

\footnotetext{
${ }^{74}$ See https://www.ecb.europa.eu/pub/pdf/other/ecb.consultation_publication_compounded_term_rates_ESTR2

02007 0567eaeb98.en.pdf? 7e5648246f1e5dff9d79d8444b5c6a03
}

${ }^{75}$ Under this approach, the spread adjustment for each existing IBOR tenor is based on the mean or median spot IBOR-adjusted RFR (calculated using the compounded setting in arrears method) spread calculated over a lookback period of e.g. 5 to 10 years. Respondents to the consultation conducted by ISDA (see http://assets.isda.org/media/2d8f2cod/92ec53e4-pdf/) preferred the compounding setting in arrears rate and the historical mean/median approach for addressing certain technical issues associated with fallbacks for GBP Libor, CHF Libor, JPY Libor, Tibor, Euro yen Tibor, USD Libor, CDOR, HIBOR, and BBSW. The majority of respondents to the final parameters consultation conducted in October 2019 by ISDA preferred a calculation of a spread adjustment based on a historical median over a five-year lookback period. Consistency of the calculation method for the spread adjustment across IBORS was also deemed as very important $\underline{\text { see }}$ https://www.isda.org/a/UaoTE/Consultation-on-Parameters-for-Fallback-Adjustments.pdf). 
authorised, this should not disincentivise users to already incorporate fallback rates in their contractual documentation and move away from EONIA. Even as EURIBOR is there to stay (at least in the medium term), the sector should use the momentum to complete all aspects to achieve a multi-rate approach within the spirit of the FSB proposal. In that sense, it should be clear to market participants that a fallback or alternative rate is not necessarily a replacement rate, but an additional safety net to be built in their products' contractual framework. The Eurozone has opted for this multi-reference rate regime. Whether this approach is most suitable for financial markets is still to be seen in the future. Adoption of a single reference rate could have the advantage that it maximizes opportunities to trade or hedge financial products that use the rate (i.e. ensuring market liquidity). Nevertheless, risk diversification amongst various rates within a multi-rate regime could also turn out to be beneficial. Regulators and scholars should continue to monitor and assess the most beneficial outcome.

Funding: This study received no specific financial support.

Competing Interests: The authors declare that they have no competing interests.

Acknowledgement: Both authors contributed equally to the conception and design of the study.

\section{REFERENCES}

Abrantes-Metz, R. M., Kraten, M., Metz, A. D., \& Seow, G. S. (2012). Libor manipulation? Journal of Banking E̊ Finance, 36(1), 136-150.

Acharya, V. V., \& Skeie, D. (2011). A model of liquidity hoarding and term premia in inter-bank markets. Journal of Monetary Economics, 58(5), 436-447.Available at: https://doi.org/10.1016/j.jmoneco.2011.05.008.

Ashton, P., \& Christophers, B. (2015). On arbitration, arbitrage and arbitrariness in financial markets and their governance: Unpacking LIBOR and the LIBOR scandal. Economy and Society, 44(2), 188-217.Available at: https://doi.org/10.1080/03085147.2015.1013352.

Beirne, J. (2012). The EONIA spread before and during the crisis of 2007-2009: The role of liquidity and credit risk. Journal of International Money and Finance, 31(3), 534-551.Available at: https://doi.org/10.1016/j.jimonfin.2011.10.005.

Bernoth, K., \& Hagen, J. v. (2004). The Euribor futures market: Efficiency and the impact of ECB policy announcements. International Finance, 7(1), 1-24.Available at: https://doi.org/10.1111/j.1367-0271.2004.00127.x.

Brainbridge, S. M. (2013). Reforming Libor: Wheatley versus the alternatives. N.Y.U. Journal of Law and Business, 9(1), 789-816.

Caporale, G. M., \& Gil-Alana, L. A. (2016). Persistence and cyclical dependence in the monthly euribor rate. Journal of Economics and Finance, 4O(1), 157-171.Available at: https://doi.org/10.1007/s 12197-014-9296-0.

Dao, A., Godwin, A., \& Ramsay, I. (2016). From enforcement to prevention: International cooperation and financial benchmark reform. Law and Financial Markets Review, 10(2), 83-101.Available at: https://doi.org/10.1080/17521440.2016.1211385.

Duffie, D., \& Stein, J. C. (2015). Reforming LIBOR and other financial market benchmarks. Journal of Economic Perspectives, 29(2), 191-2 12.Available at: https://doi.org/10.1257/jep.29.2.191.

Eisl, A., Jankowitsch, R., \& Subrahmanyam, M. G. (2017). The manipulation potential of Libor and Euribor. European Financial Management, 23(4), 604-647.

Fiszeder, P., \& Pietryka, I. (2018). Monetary policy in steering the EONIA and POLONIA rates in the Eurosystem and Poland: A comparative analysis. Empirical Economics, 55(2), 445-470.Available at: https://doi.org/10.1007/s00181-017-1285-7.

Fouquau, J., \& Spieser, P. K. (2015). Statistical evidence about LIBOR manipulation: A "Sherlock Holmes” investigation. Journal of Banking \& Finance, 50, 632-643.Available at: https://doi.org/10.1016/j.jbankfin.2014.03.039.

Gandhi, P., Golez, B., Jackwerth, J. C., \& Plazzi, A. (2019). Financial market misconduct and public enforcement: The case of Libor manipulation. Management Science, 65(11), 5268-5289.Available at: https://doi.org/10.1287/mnsc.2018.3065.

Ghosh, B., Le Roux, C., \& Verma, A. (2020). Investigation of the fractal footprint in selected EURIBOR panel banks. Business Perspectives, 15(1), 1-22.

Gyntelberg, J., \& Wooldridge, P. D. (2008). Interbank rate fixings during the recent turmoil. BIS Quarterly Review, March, 1-14. 
Hassler, U., \& Nautz, D. (2008). On the persistence of the Eonia spread. Economics Letters, 101(3), 184-187.

Henrard, M. P. (2019). LIBOR fallback and quantitative finance. Risks, 7(3), 1-15.

Hou, D., \& Skeie, D. (2014). Libor: Origins, economics, crisis, scandals, and reform (pp. 1-20). Federal Bank of New York Staff Report 667.

Kloster, A., \& Syrstad, O. (2019). Nibor, Libor and EURIBOR - all IBORs, but different. Norges Bank Staff Memo, 2(1), 1-14.

Linzert, T., \& Schmidt, S. (2011). What explains the spread between the Euro overnight rate and the ECB's policy rate? International Journal of Finance \& Economics, 16(3), 275-289.Available at: https://doi.org/10.1002/ijfe.430.

McAndrews, J., Ansani, S., \& Zhenyu, W. (2008). The effect of the term auction facility of the London inter-bank offered rate (pp. 1-54). Federal Reserve Bank of New York Staff Report 335.

McConnell, P. (2013). Systemic operational risk: The LIBOR manipulation scandal. Journal of Operational Risk, 8(3), 5999.Available at: https://doi.org/10.21314/jop.2013.127.

Michaud, F., \& Upper, C. (2008). What drives interbank rates? Evidence from the Libor panel. BIS Quarterly Revierw, March, 1-12.

Monticini, A., \& Thornton, D. L. (2013). The effect of underreporting on LIBOR rates. Journal of Macroeconomics, 37(C), 345-348.

Nautz, D., \& Offermanns, C. J. (2007). The dynamic relationship between the euro overnight rate, the ECB's policy rate and the term spread. International Journal of Finance $\mathbb{E}^{2}$ Economics, 12(3), 287-300.

Perkins, J., \& Mortby, P. (2015). Evolving financial benchmarks: The impact on legacy contracts. Journal of Securities Operations छ Custody, 7(4), 296-304.

Picault, M. (2017). Pricing the ECB's forward guidance with the EONIA swap curve. International Journal of Finance $\mathcal{E}^{\circ}$ Economics, 22(2), 129-138.Available at: https://doi.org/10.1002/ijfe.1572.

Rodriguez-Lopez, A., Fernandez-Abascal, H., Maté-Garcia, J., Rodriguez-Fernandez, J., J., R.-G., \& J., S.-G. (2020). Evaluating euribor manipulation: Effects on mortgage borrowers. Finance Research Letters. Forthcoming.

Schrimpf, A., \& Sushko, V. (2019). Beyond LIBOR: A primer on the new benchmark rates. BIS Quarterly Review March, 1-24.

Shaw, F., Murphy, F., \& O'Brien, F. G. (2016). Jumps in euribor and the effect of ECB monetary policy announcements. Environment Systems and Decisions, 36(2), 142-157.Available at: https://doi.org/10.1007/s 10669-016-9600-y.

Snider, C., \& Youle, T. (2010). Does the Libor reflect banks' borrowing costs? SSRN Working Paper, 1-25.

Taboga, M. (2014). What is a prime bank? A Euribor-OIS spread perspective. International Finance, 17(1), 51-75.Available at: https://doi.org/10.1111/infi.12044.

Vergote, O., \& Gutiérrez, J. M. P. (2012). Interest rate expectations and uncertainty during ECB governing council days: Evidence from intraday implied densities of 3-month Euribor. Journal of Banking \& Finance, 36(10), 2804-2823.

Yeoh, P. (2016). Libor benchmark: Practice, crime and reforms. Journal of Financial Crime, 23(4), 1140-1153. 